\title{
Influence of pyrolytic carbon black and pyrolytic oil made from used tires on the curing and (dynamic) mechanical properties of natural rubber (NR)/styrene-butadiene rubber (SBR) blends
}

\author{
F. Karabork ${ }^{1 *}$, S. T. Tipirdamaz ${ }^{2}$ \\ ${ }^{1}$ Aksaray University, Department of Mechanical Engineering, 68100 Aksaray, Turkey \\ ${ }^{2}$ Aksaray University, Graduate School of Natural and Applied Science, 68100 Aksaray, Turkey
}

Received 25 June 2015; accepted in revised form 26 August 2015

\begin{abstract}
Pyrolytic carbon black (CBp) and pyrolytic oil (Op) made from used tires were used in natural rubber (NR)/ styrene-butadiene rubber (SBR) blends. The effects of CBp and Op on the processing properties, the mechanical properties and the dynamic mechanical properties of the NR/SBR blends were investigated and compared with a control sample that was prepared with N550 and commercial process oil. It was found that the effect of CBp on the processing properties of the $\mathrm{NR} / \mathrm{SBR}$ blends was similar to that of N550. With the increase of the CBp content, the curing properties of the NR/SBR blends changed little. The reinforcing effect of CBp was inferior to that of N550. With the increase of the CBp content, the tensile strength, tear strength and modulus at $100 \%$ elongation of the NR/SBR vulcanizates decreased significantly. Dynamic mechanical properties of the NR/SBR blends were also affected and all samples comprising CBp have a higher $\tan \delta$ than control sample. It is suggested that the low surface area and high ash content of CBp strongly effects all of these property changes of the NR/SBR blends. The morphology and distribution of the carbon black particles are studied using a scanning electron microscope. It was also found that with the increase of the Op content, the properties of the NR/SBR blends were strongly affected due to the high sulfur content of Op, which produced a high crosslinking density.
\end{abstract}

Keywords: mechanical properties, pyrolytic carbon black, pyrolytic oil, cure characteristics, dynamical mechanical properties

\section{Introduction}

The disposal of used tires has become an important issue worldwide and represents a major environmental problem. Therefore, the development of an efficient way to utilize rubber waste is an emerging economic and environmental task faced by the rubber industry worldwide [1-4]. Rubber wastes are chemically crosslinked rubbers and are among the most difficult materials to recycle because they will not dissolve or melt. Tires are a complex mixture of numerous different materials, which include several rubbers, carbon black, steel cord and other organic and

\footnotetext{
${ }^{*}$ Corresponding author, e-mail: fazliyekarabork@hotmail.com (C) BME-PT
}

inorganic components [5]. This is another reason why used tires are not easily recycled.

Over the years, different alternatives for tire recycling, such as repeated use (retreading), energy recycling (incineration) and grinding have been used, but none of these applications are capable of totally eliminating the waste disposal problem while resulting in adequate profitability. Tire pyrolysis, at present, is an attractive and challenging area of research. The pyrolysis processing of used tires is considered to be an environmentally acceptable and promising disposal method with its high energy recovery and low pollution emission. 
Basically, the pyrolysis process is the thermal decomposition of organic wastes at high temperatures in an oxygen-free environment. The pyrolysis process produces three different fractions: a solid fraction known as char or pyrolytic carbon black (33-38 wt \%), a liquid fraction known as pyrolytic oil (38-55 wt \%) and a gas fraction (10-30 wt\%) [6].

Pyrolytic oil may be used as an industrial fuel after extracting chemical materials. CBp can be used as a filler in asphalt for rheological modification $[7,8]$. There are several papers in the literature devoted to the study of tire pyrolysis in liquids and pyrolytic carbon black, and each presents its particular experimental procedure and characterization [6, 9-13] but do not discuss using the products as a process oil and reinforcement additive in rubber compounds, which is focus of this study. In recent years, Du and coworkers [14, 15], Cataldo [16] and Norris et al. [17] tested CBp in new rubber compounds. Jie et al. [18], Jie et al. [19] and Delchev et al. [20] investigated the modification of CBp and studied the effect of modified CBp on the properties of NR and SBR vulcanizates. There are fewer reports about Op used in rubbers than about $\mathrm{CBp}[12,21]$.

In this paper, we studied the characteristics of $\mathrm{CBp}$ and $\mathrm{Op}$ and focused our efforts on the application of $\mathrm{CBp}$ and $\mathrm{Op}$ in rubber compounds. Rubber compounds are made from a blend of NR/SBR by using several additives. The effects of CBp and Op on the processing properties of NR/SBR compounds and the mechanical and dynamical mechanical properties of NR/SBR vulcanizates were systematically studied and compared with those of commercial carbon black and commercial processing oil.

\section{Experimental}

\subsection{Materials and characterization}

The styrene butadiene rubber (SBR 1502; bound styrene (wt\%), 22.5, Mooney Viscosity (ML 1+4) at $\left.100{ }^{\circ} \mathrm{C}, 52\right)$, the natural rubber SIR20 (NR) and other curing ingredients (Sulfur, N-Cyclohexyl-2benzothiazolesulfenamide (CBS), zinc oxide ( $\mathrm{ZnO})$ and stearic acid) used in this study, were supplied from Yuksel Rubber Co., Ltd., Konya, Turkey, these ingredients were produced by Bayer AG (Germany). The original carbon black (N550) used in this study was supplied by Tupras Co., Turkey. Octobus N821 used as an original process oil was supplied from Petroyag Chemicals Co., Kocaeli, Turkey. Pyrolytic carbon black (CBp) and pyrolytic oil (Op) were sup- plied by a local tire pyrolysis plant (Tam Rubber Co., Aksaray, Turkey). The CBp and Op were produced from the used tires by using a fixed bed reactor at a temperature of $500-550^{\circ} \mathrm{C}$ in the supplying plant. The CBp was used as a filler in the rubber compound formulation without removing ash or any other purification. The determination of the ash content in $\mathrm{CBp}$ was determined according to ASTM D1506. The elemental composition of the CBp was determined by using a Thermo Scientific FLASH 2000 elemental analyzer. The surface area of the CBp was measured using a BET (Brunauer, Emmett and Teller) tester (Quantachrome NovaWin2). The physical properties of the pyrolysis oils were determined according to standards for sulfur content (EN ISO 8754) kinematic viscosity (ASTM D445) and density (ASTM D5002).

\subsection{Preparation of rubber compounds}

The formulations of the compounds are presented in Table 1. SBR and NR were used in the same ratio $(50 / 50 \mathrm{phr})$ in all formulations. The amounts of the other additives ( $\mathrm{ZnO}$, stearic acid, $\mathrm{CBS}$ and sulfur) in the formulations are based on $100 \mathrm{~g}$ of rubber. NR/SBR, other additives and various proportions of the CBp or Op were mixed for 15 minutes on an open two-roll mixing mill at room temperature. The first formulation, which is called the control sample, does not contain CBp or Op. Original carbon black and original process oil were partially replaced by the $\mathrm{CBp}$ and $\mathrm{Op}$ in the other formulations, as shown in Table 1. Samples were identified as PC and PO followed by the sample number, corresponding to the introduction of pyrolytic carbon black and pyrolytic oil, respectively. The cure characteristics of the rubber compounds were characterized using a rheometer, Beijing RADE MR-C3, at $170{ }^{\circ} \mathrm{C}$.

\subsection{Measurement of mechanical properties}

The tensile properties of the NR/SBR vulcanizates were measured with a Shimadzu AG-IC tensile testing machine, according to ASTM D412, at a testing speed of $500 \mathrm{~mm} / \mathrm{min}$. Dumbbell-shaped specimens were punched from compression-molded sheets. The tear strength was tested according to ASTM D624 C with a Gibitre (Tensor Check Profile PC) tensile testing machine. The compression set test was carried out at $100^{\circ} \mathrm{C}$ for $24 \mathrm{~h}$, in agreement with ASTM D395-03. The Shore A hardness was measured according to ASTM D 2240. At least three or 
Table 1. Formulations of the rubber compounds

\begin{tabular}{|l|c|c|c|c|c|c|c|c|c|}
\hline \multicolumn{1}{|c|}{ Sample code/Ingredients (phr $\left.{ }^{*}\right)$} & Control & PC1 & PC2 & PC3 & PC4 & PO1 & PO2 & PO3 & PO4 \\
\hline NR/SBR & $50 / 50$ & $50 / 50$ & $50 / 50$ & $50 / 50$ & $50 / 50$ & $50 / 50$ & $50 / 50$ & $50 / 50$ & $50 / 50$ \\
\hline Carbon black (N550) & 50 & 43.75 & 37.5 & 25 & 0 & 50 & 50 & 50 & 50 \\
\hline Pyrolytic carbon black (CBp) & 0 & 6.25 & 12.5 & 25 & 50 & - & - & - & - \\
\hline Process oil & 20 & 20 & 20 & 20 & 20 & 17.5 & 15 & 10 & 0 \\
\hline Pyrolytic oil (Op) & 0 & - & - & - & - & 2.5 & 5 & 10 & 20 \\
\hline ZnO & 3 & 3 & 3 & 3 & 3 & 3 & 3 & 3 & 3 \\
\hline Stearic acid & 1 & 1 & 1 & 1 & 1 & 1 & 1 & 1 & 1 \\
\hline CBS & 1.8 & 1.8 & 1.8 & 1.8 & 1.8 & 1.8 & 1.8 & 1.8 & 1.8 \\
\hline Sulfur & 1.75 & 1.75 & 1.75 & 1.75 & 1.75 & 1.75 & 1.75 & 1.75 & 1.75 \\
\hline
\end{tabular}

*parts per hundred rubber

five samples for each composition were tested, and the average values are reported.

\subsection{Dynamic mechanical analysis (DMA)}

The dynamic mechanical properties of the NR/SBR vulcanizates were measured with a Perkin Elmer DMA7e in tension mode. The frequency used in this experiment was $1 \mathrm{~Hz}$, with a temperature range from -90 to $60{ }^{\circ} \mathrm{C}$ and a heating rate of $5^{\circ} \mathrm{C} / \mathrm{min}$.

\subsection{Morphology}

The morphology of the original carbon black and CBp surfaces and the fracture surfaces of the NR/ SBR vulcanizates that were fractured in liquid nitrogen were evaluated with a Fei Quanta 250 FEG scanning electron microscope (SEM). Prior to this operation, the specimens were coated with a thin gold layer.

\section{Results and discussion}

\subsection{Characterization of the pyrolytic carbon black and pyrolytic oil}

The most important characteristics of the CBp produced by the tire pyrolysis plant are given in Table 2 . An important difference between N550 and CBp is the high ash content, which includes inorganic components. The ash content of $\mathrm{CBp}$ is $15.36 \%$, which is much more than that of N550. The most important sources of the inorganic components in $\mathrm{CBp}$ are usually $\mathrm{ZnO}$ and $\mathrm{S}$, which are used as a curing catalyst and curing agent, respectively, and sometimes mineral fillers or additives such as $\mathrm{SiO}_{2}$ and $\mathrm{Al}_{2} \mathrm{O}_{3}$. The composition of the inorganic components in the $\mathrm{CBp}$ also depends on the pyrolysis conditions and the quality of the tire feed. The surface area of N550 and CBp was 42 and $30.4 \mathrm{~m}^{2} / \mathrm{g}$, respectively. The lower surface area of the $\mathrm{CBp}$ was most probably due to a blockage of a portion of the carbon black
Table 2. Characteristics of pyrolytic carbon black and commercial carbon black

\begin{tabular}{|l|c|c|c|c|c|}
\hline & $\begin{array}{c}\text { Specific surface area } \\
{\left[\mathbf{m}^{\mathbf{2}} / \mathbf{g}\right]}\end{array}$ & $\begin{array}{c}\text { Ash } \\
{[\mathbf{\%}]}\end{array}$ & $\begin{array}{c}\text { Sulfur } \\
{[\mathbf{\%}]}\end{array}$ & $\begin{array}{c}\mathbf{C} \\
{[\mathbf{\%}]}\end{array}$ & $\begin{array}{c}\mathbf{H} \\
{[\mathbf{\%}]}\end{array}$ \\
\hline $\mathrm{CBp}$ & 30.4 & 15.36 & 1.45 & 79.15 & 4.91 \\
\hline $\mathrm{N} 550$ & 42 & 0.2 & 0.5 & 92.36 & - \\
\hline
\end{tabular}

Table 3. Characteristics of pyrolytic oil and commercial oil

\begin{tabular}{|c|c|c|c|}
\hline & $\begin{array}{l}\text { Specific gravity } \\
{\left[\mathrm{g} / \mathrm{cm}^{3}\right], \text { at } 15^{\circ} \mathrm{C}}\end{array}$ & $\begin{array}{l}\text { Kinematic viscosity } \\
{\left[\mathrm{mm}^{2} / \mathrm{s}\right], \text { at } 100^{\circ} \mathrm{C}}\end{array}$ & $\begin{array}{c}\text { Sulfur } \\
{[\%]}\end{array}$ \\
\hline Op & 0.937 & 0.86 & 2.1 \\
\hline Octobus N821 & 0.908 & 8.8 & $<0.01$ \\
\hline
\end{tabular}

surface by carbonaceous deposits [22, 23]. The sulfur content of approximately $1.45 \%$ is consistent with literature $[6,13,24]$ reports. The residual $\mathrm{S}$ in $\mathrm{CBp}$ was attributed to the sulfur in the recipe of the tires.

In addition to the ash content and surface area, the surface morphology also plays an important role in the characterization of the carbon black. SEM photos of N550 and CBp are shown in Figure 1a and 1b. The surface morphology of the commercial carbon black shows a rough surface. $\mathrm{CBp}$ has a smooth surface due to the deposition of ash and carbonaceous deposits on the surface $[22,23]$.

The pyrolytic oil was characterized, and the results are presented in Table 3 . The specific gravity of Op was found to be higher and the viscosity lower than that of commercial oil. As expected, the sulfur amount in Op was higher than that of commercial oil. This may be explained based on the high content of sulfur in the vulcanization recipe.

\subsection{Cure characteristics}

The vulcanization curves of the NR/SBR compounds with the additions of $\mathrm{CBp}$ and $\mathrm{Op}$ are shown in Figure $2 a$ and $2 b$, respectively. There exist three regions along the vulcanization curves of the compounds 


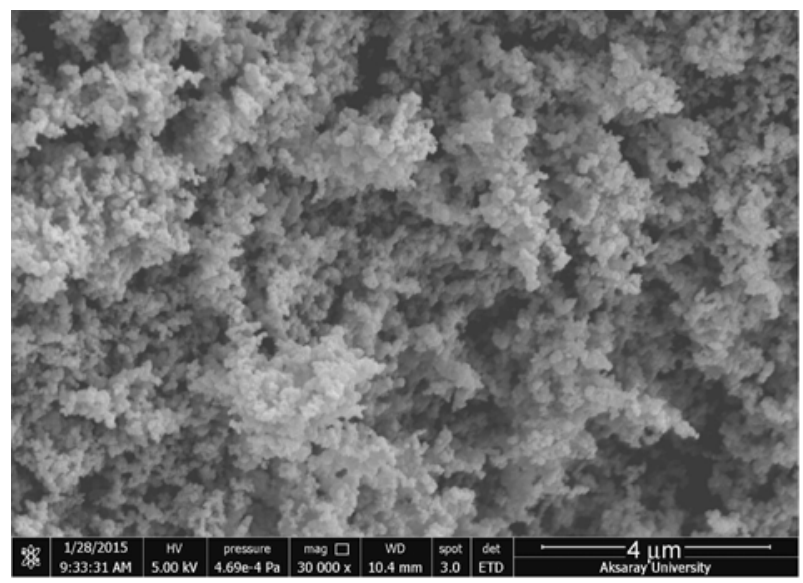

a)

Figure 1. SEM photographs of (a) N550 (b) CBp

containing CBp. The first region is the scorch delay, an induction region during which the majority of the accelerator reactions occur. In this region, the scorch time $\left(t s_{2}\right)$ of the compounds was little or not affected by the addition of the CBp. The minimum torque $\left(M_{\mathrm{L}}\right)$, measure of the rubber's resistance to flow during processing increased slightly with the addition of $50 \mathrm{phr} \mathrm{CBp}$. This indicates that the processing of rubber compounds containing only $\mathrm{CBp}$ was more difficult than for blends containing commercial carbon black. The second region is the curing reaction period. The optimum cure time $\left(t_{90}\right)$, the vulcanization time required to obtain a product with optimum physical characteristics, slightly decreased with the addition of CBp. With the use of only CBp, $t_{90}$ has the lowest value. This is probably due to the some sulfur content of the pyrolytic carbon black. The final region of the vulcanization process is dependent on the crosslink network stability. The modulus can reach a stable plateau (ideal), it can continue to increase (marching modulus), or it can decline (cure reversion). During this period, with the

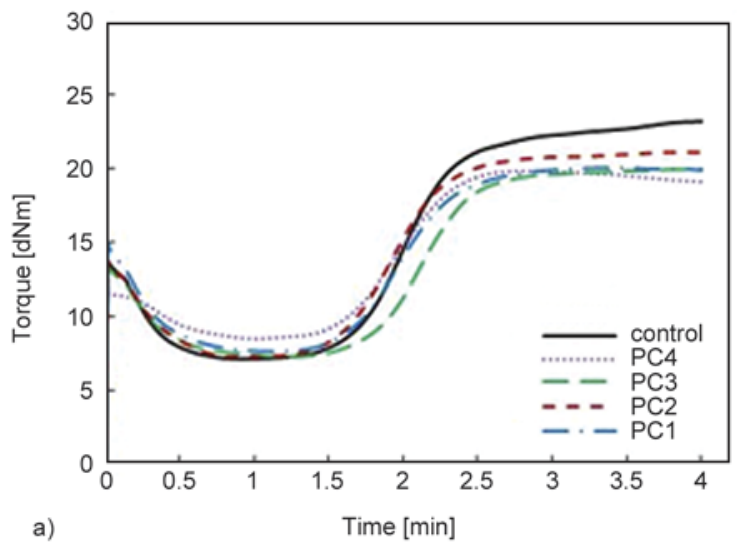

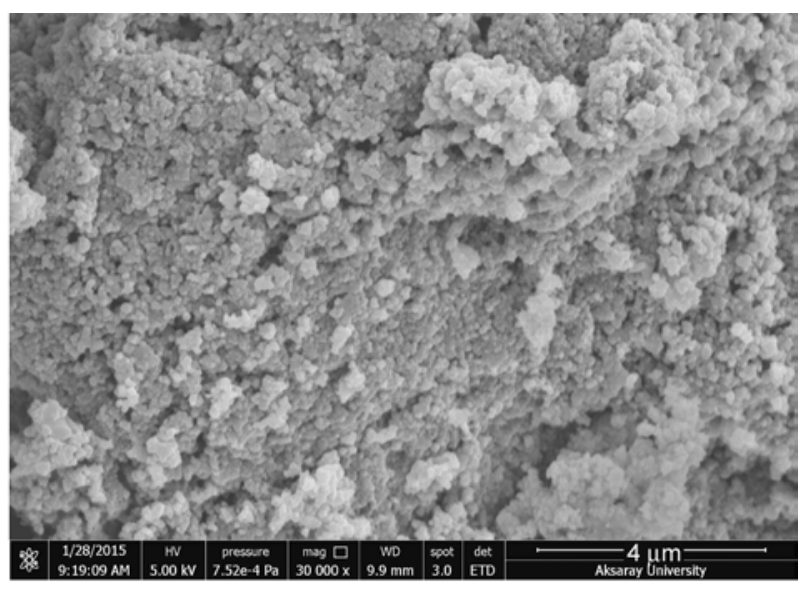

b)

increase of the $\mathrm{CBp}$ content, the maximum torques of the SBR/NR compounds, which are the measure of the compound's final stiffness, are lower than that of the control sample. This should be attributed to the poor reinforcing effect of the CBp in NR/SBR compounds, associated with its smaller surface area [25]. The effect of the Op on the vulcanization curves of the NR/SBR compounds is different from that of $\mathrm{CBp}$, as shown in Figure $2 \mathrm{~b}$. The vulcanization curves also have three regions, as in Figure 2a, but the scorch time, optimum cure time, minimum torque and maximum torque of the compounds was significantly affected by the addition and increases in the amount of Op. $t s_{2}$ and $t_{90}$ decreased, while $M_{\mathrm{L}}$ and $M_{\mathrm{H}}$ increased. The decreases of $t s_{2}$ and $t_{90}$ may be because the content of sulfur in Op is higher than that of the original process oil. The Op can be considered as the sulfur donor, so that the formation of sulfur cross-links was accelerated. The vulcanization process occurs more rapidly when pyrolytic oil is used, as was reported earlier [12]. The increasing of $M_{\mathrm{H}}$ may indicate that NR/SBR compounds loaded

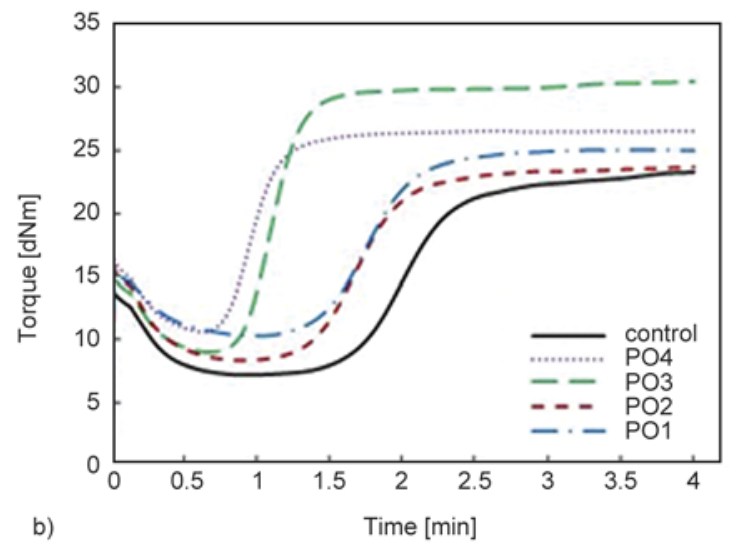

Figure 2. Effects of the (a) CBp and (b) Op on the vulcanization curves of the NR/SBR compounds 
with Op tend to become stiff due to the high crosslinking density produced by sulfur curing.

\subsection{Mechanical properties}

The mechanical properties of the NR/SBR vulcanizates are summarized in Table 4 and 5. CBp and Op showed different effects on the mechanical properties for NR/SBR vulcanizates.

With the increase of the CBp content, all of the properties of the NR/SBR vulcanizates (tensile strength, elongation at break, modulus, tear strength and hardness) except for compression set are decreased. At the higher levels, the CBp (50 phr) gives a larger drop in the mechanical properties relative to the commercial carbon black. The compression set, a measure of the material's elasticity after a prolonged action of compression, gradually increased with the addition of CBp. There are several reasons for these results, such as the surface area and ash content of the pyrolytic carbon black. All of these parameters play a role in rubber reinforcement through different mechanisms such as interfacial interaction between the carbon black and rubber $[25,26]$. The measurement of the surface area has been shown to be lower for CBp than for N550 carbon black (approximately $30.4 \mathrm{~m}^{2} / \mathrm{g}$ versus $42 \mathrm{~m}^{2} / \mathrm{g}$ for N550). It is well known that the degree of reinforcement increases with a decrease in particle size or an increase in surface area [25]. As the surface area of the carbon black increases, the degree of entanglement between the rubber chains and carbon black particles as well as the degree of crosslinking increases [27, 28]. Therefore, the surface area of carbon black is of great importance for the density of the physical crosslinking. Additionally, in filled rubbers, the fillers act as stress concentrators. The smaller the particle size of the fillers, the more efficient will be the stress transfer from the matrix to the fillers. [25, 29]. Hence, it is understandable that the development of a large polymer-filler interface is the most important factor for the degree of reinforcement provided by the filler [28].

Another factor that may explain the insufficient reinforcing effect of $\mathrm{CBp}$ is the high ash content of the pyrolytic carbon black, which limits its use as a reinforcement filler for rubber manufacturing. This means that the real amount of carbon black added to the rubber vulcanizates is only a part of that used in the reference compound filled with N550. The ash content also leads to a low structure, which is the other parameter that affects the reinforcing properties of carbon black in a rubber recipe [16]. There-

Table 4. Effects of pyrolytic carbon black content on mechanical properties of NR/SBR vulcanizates

\begin{tabular}{|ll|c|r|r|r|r|}
\hline & & Control & PC1 & PC2 & PC3 & PC4 \\
\hline Pyrolytic carbon black & {$[\mathrm{phr}]$} & 0 & 6.25 & 12.5 & 25 & 50 \\
\hline Elongation at break & {$[\%]$} & 664.31 & 570.28 & 548.63 & 539.82 & 514.17 \\
\hline Tensile strength & {$\left[\mathrm{N} / \mathrm{mm}^{2}\right]$} & 10.91 & 6.37 & 5.53 & 5.13 & 2.03 \\
\hline $100 \%$ Modulus & {$\left[\mathrm{N} / \mathrm{mm}^{2}\right]$} & 1.68 & 1.45 & 1.42 & 1.35 & 0.82 \\
\hline $200 \%$ Modulus & {$\left[\mathrm{N} / \mathrm{mm}^{2}\right]$} & 3.04 & 2.49 & 2.34 & 2.21 & 1.23 \\
\hline $300 \%$ Modulus & {$\left[\mathrm{N} / \mathrm{mm}^{2}\right]$} & 4.62 & 3.50 & 3.20 & 2.88 & 1.45 \\
\hline Hardness Shore-A) & & 52 & 51 & 49 & 45 & 42 \\
\hline Tear strength & {$\left[\mathrm{N} / \mathrm{mm}^{2}\right]$} & 36.9 & 28.8 & 25.6 & 22.7 & 14.3 \\
\hline Compression set & {$[\%]$} & 31 & 34 & 34 & 35 & 41 \\
\hline Density & {$\left[\mathrm{g} / \mathrm{cm}^{3}\right]$} & 1.09 & 1.1 & 1.08 & 1.06 & 1.05 \\
\hline
\end{tabular}

Table 5. Effects of pyrolytic oil content on mechanical properties of NR/SBR vulcanizates

\begin{tabular}{|ll|c|c|c|c|c|}
\hline & & Control & PO1 & PO2 & PO3 & PO4 \\
\hline Pyrolytic oil & {$[\mathrm{phr}]$} & 0 & 2.5 & 5 & 10 & 20 \\
\hline Elongation at break & {$[\%]$} & 664.31 & 697.10 & 748.69 & 770.02 & 732.67 \\
\hline Tensile strength & {$\left[\mathrm{N} / \mathrm{mm}^{2}\right]$} & 10.91 & 10.41 & 10.29 & 9.65 & 11.90 \\
\hline $100 \%$ Modulus & {$\left[\mathrm{N} / \mathrm{mm}^{2}\right]$} & 1.68 & 1.72 & 1.74 & 1.51 & 2.20 \\
\hline $200 \%$ Modulus & {$\left[\mathrm{N} / \mathrm{mm}^{2}\right]$} & 3.04 & 3.05 & 2.97 & 2.76 & 3.96 \\
\hline $300 \%$ Modulus & {$\left[\mathrm{N} / \mathrm{mm}^{2}\right]$} & 4.62 & 4.47 & 4.31 & 3.89 & 5.62 \\
\hline Hardness (Shore-A) & & 52 & 54 & 55 & 62 & 58 \\
\hline Tear strength & {$\left[\mathrm{N} / \mathrm{mm}^{2}\right]$} & 36.9 & 35.1 & 34.3 & 26.6 & 46 \\
\hline Compression set & {$[\%]$} & 31 & 32 & 32 & 36 & 35 \\
\hline Density & {$\left[\mathrm{g} / \mathrm{cm}^{3}\right]$} & 1.09 & 1.08 & 1.07 & 1.11 & 1.08 \\
\hline
\end{tabular}


fore, the reinforcement effect of CBp is lower compared with that of commercial carbon black. These results are supported by SEM images of the carbon blacks and the fracture surface of the vulcanizates (Figures 1 and 5).

On the other hand, the mechanical properties of NR/ SBR vulcanizates obtained from Op loading are quite different from those obtained using $\mathrm{CBp}$, as shown in Table 5. The tensile strength, modulus and tear strength decreased at the loadings of $2.5,5$ and $10 \mathrm{phr}$, but all of these properties increased remarkably with a loading of over $10 \mathrm{phr}$. In contrast, the elongation at break, hardness and compression set first increased and then decreased with the additional Op loading. It is well known that the softening effect of process oils leads to improved processing through easier filler incorporation and dispersion, enabling lower processing temperatures and better flow properties [30]. In our opinion, the change in the mechanical properties with the increase of $\mathrm{Op}$ content is due to the adverse influence on processing, such as difficult dispersion, slow filler incorporation and inferior flow, due to the low level of purity of Op. However, with the addition of $20 \mathrm{phr}$ Op, the mechanical properties remarkably changed due to the effect of the increasing crosslinking density in the NR/SBR vulcanizates because of the high sulfur content of Op. These results indicate that the pyrolytic and commercial oils interfere with the vulcanized network in different ways. This result is supported by the prior work by Roy et al. [12], as well as by the cure properties of NR/SBR compounds.

\subsection{Dynamic mechanical properties}

The dynamic mechanical behavior of the rubber vulcanizates is the other indicator of the reinforcing

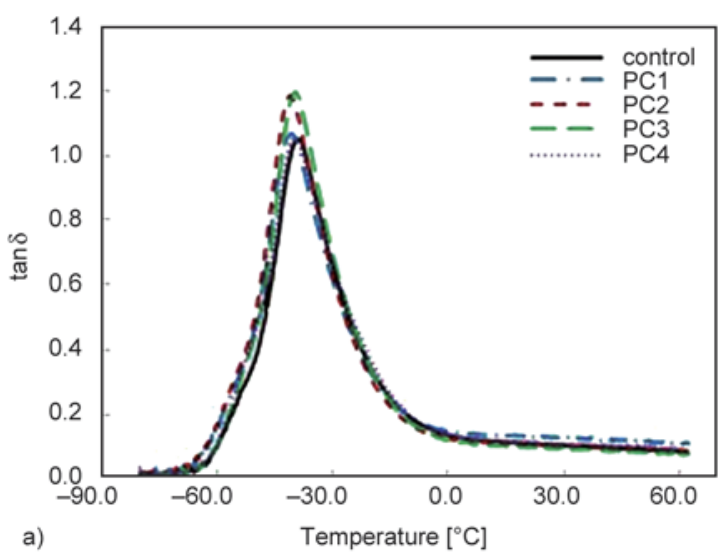

effect of CBp. The mechanical loss tangent $(\tan \delta)$ is the ratio between the dynamic loss modulus $\left(E^{\prime \prime}\right)$ and the dynamic storage modulus $\left(E^{\prime}\right)\left(\tan \delta=E^{\prime \prime} / E^{\prime}\right)$. It naturally represents the macromolecular mobility of the chains and the polymer phase transitions [31-33]. It is accepted that a higher $\tan \delta$ indicates greater mechanical losses, which are related to the high energy input required for the motion of the molecular chains of the polymer as the transition is approached [34, 35].

Figure 3 a shows the effect of CBp loading on $\tan \delta$ as a function of the test temperature. It is well known that the $\tan \delta$ peak corresponds to the glass transition temperature $\left(T_{\mathrm{g}}\right)$. It can be seen that $\tan \delta$ shows a peak at temperatures between -60 and $-10{ }^{\circ} \mathrm{C}$, known as a transition region. By incorporating $\mathrm{CBp}$, the height of the $\tan \delta$ peak and the glass transition temperature change slightly due to the rubber-filler interaction. It is well known that the rubber-filler interaction increases with the increasing surface area of carbon black, reducing the chain mobility and transferring less mechanical energy to the rubber molecules, so that $\tan \delta$ max decreases [36]. The $\tan \delta$ first increased and then decreased by increasing the CBp level, but all samples comprising CBp have a higher $\tan \delta$ than control sample. The results also suggest that increasing the CBp content causes a decrease in the elastic behavior (increased tan $\delta \max$ ) due to the decreased real amount of carbon black upon increasing the $\mathrm{CBp}$ content. The storage moduli were effected by the amount of CBp added as shown in Figure 3b. Accordingly [37], the hydrodynamic reinforcement occurs in the rubber composites filled with the conventional fillers such as $\mathrm{CB}$, giving rise to an increase in the modulus in polymer matrix. The storage modulus $\left(E^{\prime}\right)$ values decreased with the

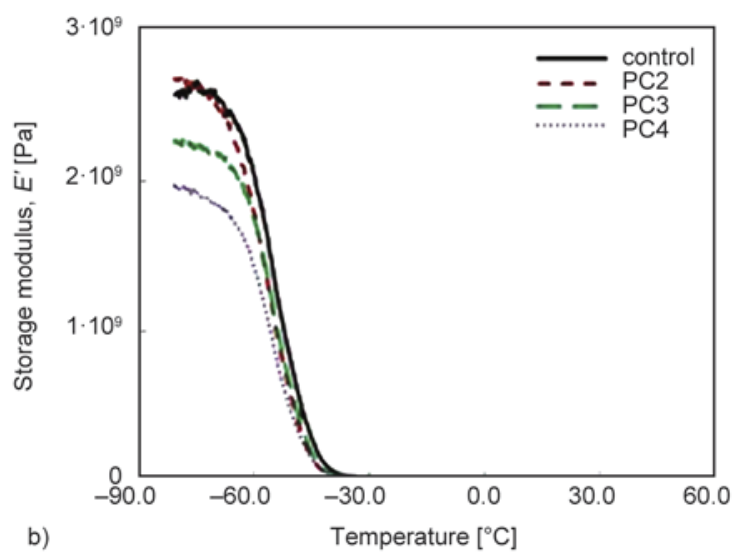

Figure 3. Effect of $\mathrm{CBp}$ on (a) $\tan \delta$ and (b) storage modulus as a function of temperature for NR/SBR vulcanizates 
increasing CBp amount. This is due to the weaker reinforcing effect of $\mathrm{CBp}$ than that of N550s in the NR/SBR matrix as discussed earlier. The obtained results for the dynamic mechanical properties of the investigated NR/SBR vulcanizates can be explained by the difference in the morphology, structure and surface area of the two types of fillers.

The height of the $\tan \delta$ peak decreased and the storage modulus $\left(E^{\prime}\right)$ values increased as the Op content increased (Figure $4 \mathrm{a}$ and $4 \mathrm{~b}$ ). The results suggest that increasing the Op content caused an increase in the elastic behavior. This is probably due to the increased crosslinking density. The results obtained for the dynamic mechanical properties of the investigated NR/SBR vulcanizates containing Op can be explained by the difference in the plasticizer effects of Op and commercial oil.

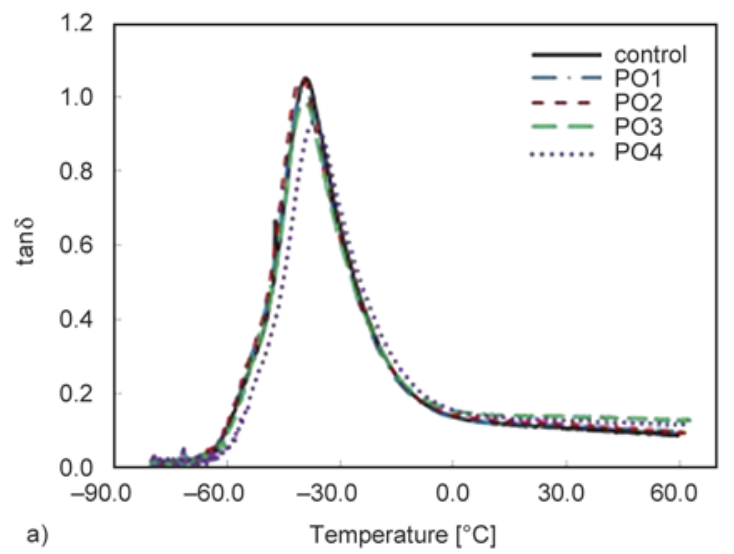

In addition, the results of DMA testing of the rubber compounds has also been shown to be a predictor of the compound's performance [38]. SBR/NR blends are used in tire tread compounds for passenger car due to the good wet traction and rolling resistance [39]. Comparison of the $\tan \delta$ values of the compounds from this study and other studies was given in Table 6. A high $\tan \delta$ at $0{ }^{\circ} \mathrm{C}$ is correlating with good wet traction and a low $\tan \delta$ at $60^{\circ} \mathrm{C}$ correlating with low rolling resistance [40]. Generally, it is difficult to obtain a high $\tan \delta$ at $0{ }^{\circ} \mathrm{C}$ and at the same time a low $\tan \delta$ at $60{ }^{\circ} \mathrm{C}$. Therefore, a balance between the $\tan \delta$ values at 0 and $60^{\circ} \mathrm{C}$ may suggest the suitable tire tread compound [40]. Both the $\tan \delta$ at $0{ }^{\circ} \mathrm{C}$ and the $\tan \delta$ at $60{ }^{\circ} \mathrm{C}$ are obtained in this study is lower than commercial tire treads [38]. The

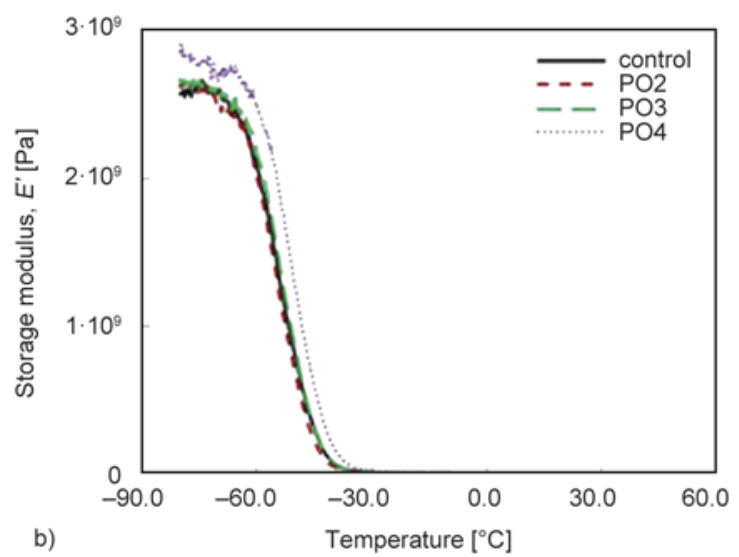

Figure 4. Effect of Op on (a) $\tan \delta$ and (b) storage modulus as a function of temperature for NR/SBR vulcanizates

Table 6. Comparison of the $\tan \delta$ values of the compounds

\begin{tabular}{|c|c|c|c|c|c|c|c|c|}
\hline & \multicolumn{3}{|c|}{ This study } & \multicolumn{5}{|c|}{ Literature } \\
\hline & \multirow{2}{*}{ Control } & \multirow{2}{*}{ PC4 } & \multirow{2}{*}{ PO4 } & \multirow{2}{*}{$\begin{array}{l}\text { Waddel } \text { et al., } \\
1990 \text { [39] }\end{array}$} & \multirow{2}{*}{$\begin{array}{c}\text { Kim et al., } \\
2009[41]\end{array}$} & \multicolumn{3}{|c|}{ Terrill et al., $2010[38]^{*}$} \\
\hline & & & & & & $(3287)^{* * *}$ & $(3229)^{* * *}$ & $(3034)^{* * 3}$ \\
\hline \multicolumn{9}{|c|}{ Ingredients [phr] } \\
\hline SBR & 50 & 50 & 50 & 50 & 100 & \multirow{10}{*}{ - } & \multirow{10}{*}{ - } & \multirow{10}{*}{ - } \\
\hline NR & 50 & 50 & 50 & 50 & - & & & \\
\hline Carbon black & 50 & - & 50 & 45 & 35 & & & \\
\hline Silica & - & - & - & - & 20 & & & \\
\hline Pyrolytic carbon black (CBp) & - & 50 & - & - & - & & & \\
\hline Process oil & 20 & 20 & - & 9 & 2 & & & \\
\hline Pyrolytic oil (Op) & - & - & 20 & - & - & & & \\
\hline $\mathrm{ZnO}$ & 3 & 3 & 3 & 3 & 3 & & & \\
\hline Stearic acid & 1 & 1 & 1 & 1 & 1.6 & & & \\
\hline Sulfur & 1.75 & 1.75 & 1.75 & 1.6 & 1 & & & \\
\hline \multicolumn{9}{|c|}{ Dynamic mechanical properties } \\
\hline $\tan \delta$ at $0^{\circ} \mathrm{C}$ & 0.138 & 0.136 & 0.155 & 0.139 & 0.266 & 0.174 & 0.184 & 0.226 \\
\hline $\tan \delta$ at $60^{\circ} \mathrm{C}$ & 0.090 & 0.097 & 0.115 & - & 0.169 & 0.108 & 0.119 & 0.178 \\
\hline Ratio of the $\tan \delta\left(0^{\circ} \mathrm{C}\right) / \tan \delta\left(60^{\circ} \mathrm{C}\right)$ & 1.53 & 1.40 & 1.35 & - & 1.57 & 1.61 & 1.55 & 1.27 \\
\hline
\end{tabular}

*Terrill et al. [38], 2010, forty-eight commercial tire treads were investigated by authors for prediction of rolling resistance and wet traction. Three samples were given here.

${ }^{* *}$ Barcode numbers are given by the authors. 
ratios of the $\tan \delta\left(0{ }^{\circ} \mathrm{C}\right) / \tan \delta\left(60^{\circ} \mathrm{C}\right)$ were obtained in this study are well satisfied with the literature.

\subsection{Morphology}

Scanning electron micrographs of the fractured surfaces of rubber vulcanizates containing N550 and $\mathrm{CBp}$ are shown in Figure 5. The carbon black mainly exists as aggregates in the rubber matrix [42]. In the SEM of all of the NR/SBR vulcanizates, carbon black aggregates can be easily distinguished. The carbon black aggregates for N550 have smaller sizes than the CBp aggregates. As Table 2 demonstrates, N550 has a higher specific surface area than CBp. With the increase of the $\mathrm{CBp}$ content, the interfaces between the CBp aggregates and the NR/SBR matrix are apparent. Desirable interaction between the molecules of rubber and carbon black does not exist between the CBp and the NR/SBR matrix due to the surface properties of $\mathrm{CBp}$ such as its surface area and the ash on the surface. Hence, CBp has a weaker reinforcing performance than that of N550s in the NR/SBR matrix, which is in agreement with the other conclusions from our experimental results.

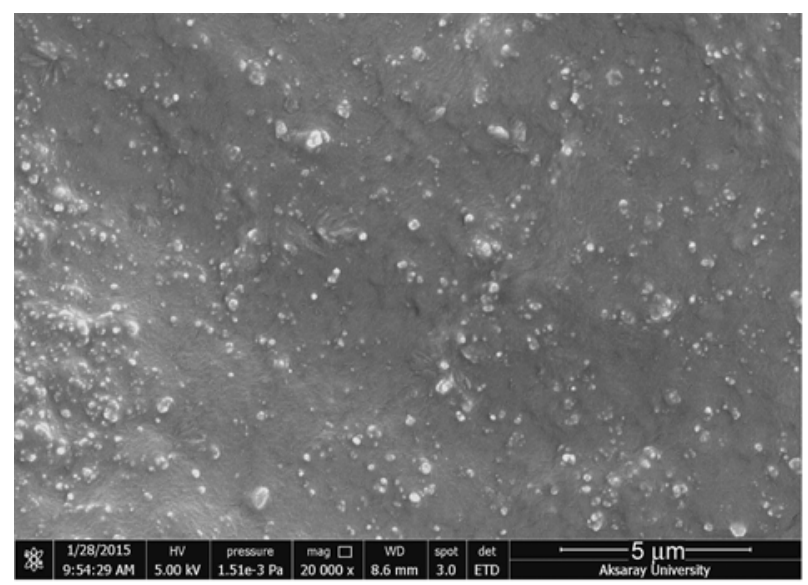

a)

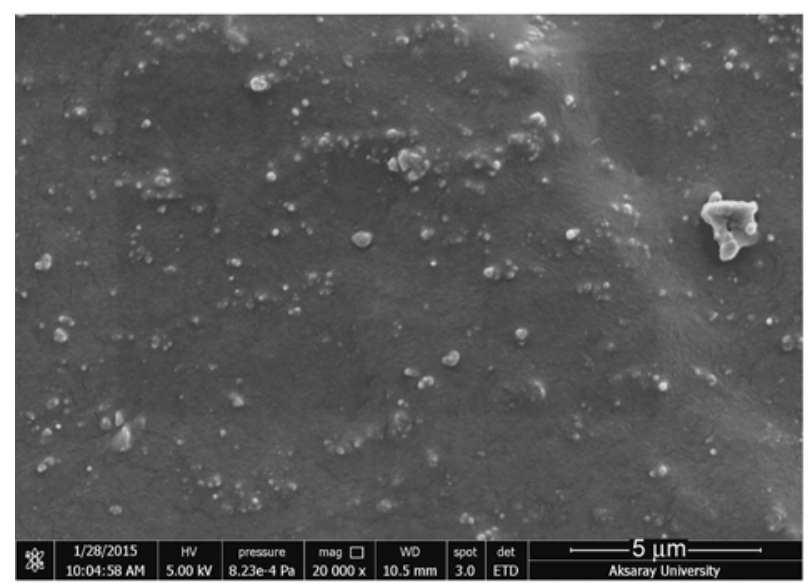

c)
On the other hand, the quality of the carbon black containing rubber is extremely dependent on the degree of dispersion the carbon black particles achieved inside the rubber matrix [43]. With the increased CBp loading the fractured surfaces show that the filler is nonuniformly dispersed in the NR/ SBR matrix, and the particle size distribution is extended. These results, as seen from Figure 5, lead to the low mechanical properties.

\section{Conclusions}

In this work, the properties of the NR/SBR blends with the addition of $\mathrm{CBp}$ or Op were studied. The following conclusions can be drawn:

- The processability of the blends did not change meaningfully with the increase of the CBp content. However, the processability of the blends is significantly affected by the addition and increases in the amount of the Op. $t s_{2}$ and $t_{90}$ were decreased due to the high sulfur content of Op. Vulcanization reactions occurred more rapidly, and the high sulfur content also affected $M_{\mathrm{L}}$ and $M_{\mathrm{H}}$, which increased due to the high crosslinking density.

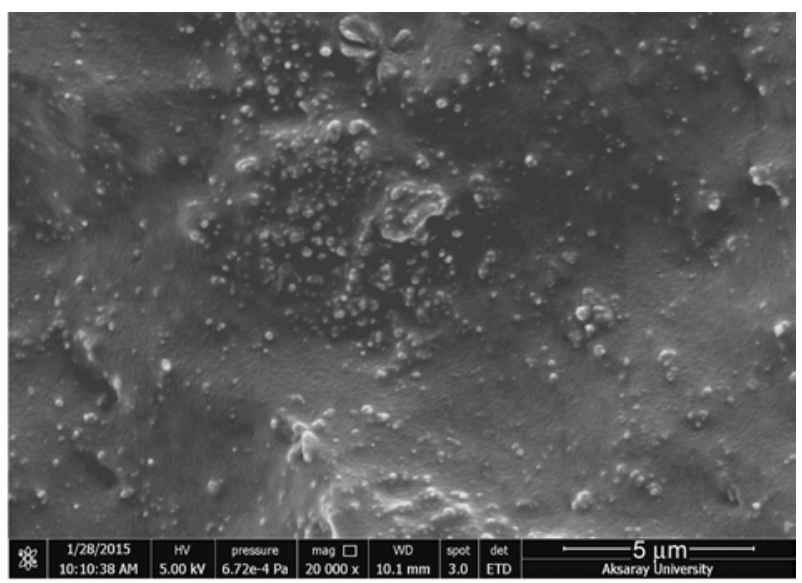

b)

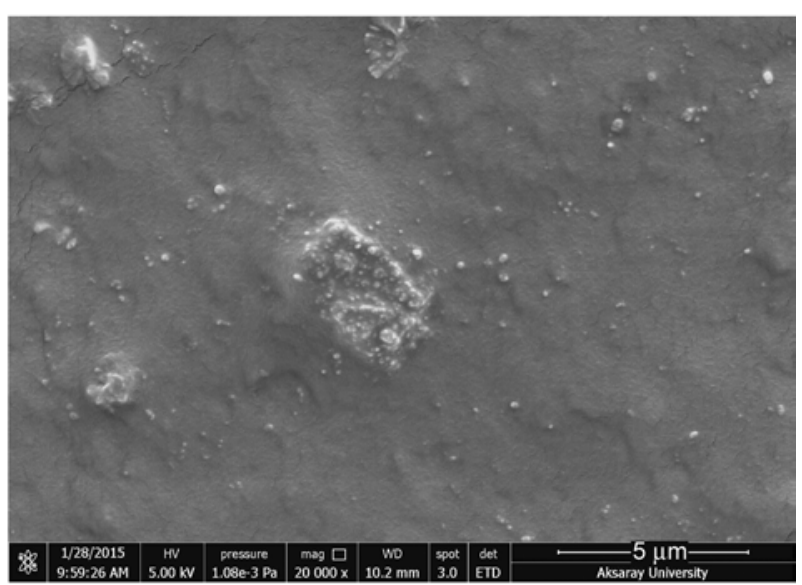

d)

Figure 5. SEM photographs of NR/SBR vulcanizates (a) control (b) PC2 (c) PC3 (d) PC4 
- The NR/SBR vulcanizates with increasing CBp content have lower mechanical properties compared with the commercial $\mathrm{CB}$ due to the high ash content and low surface area of the pyrolytic carbon black. From this result, it has been found that CBp cannot replace commercial carbon black in a recipe at equal parts, but it may be added in a small amount, or the drop in the mechanical properties may become unacceptable. On the other hand, the mechanical properties of NR/SBR vulcanizates obtained from Op loading were significantly affected by the addition and increases in the amount of the Op. The tensile strength, modulus and tear strength decreased at loadings of 2.5, 5 and $10 \mathrm{phr}$, but all of these properties increased remarkably with a loading of over $10 \mathrm{phr}$. In contrast, the elongation at break, hardness and compression set first increased and then decreased with the additional Op loading. This is due to the low influence on the processing because of the chemical composition.

- With the increase in $\mathrm{CBp}, \mathrm{NR} / \mathrm{SBR}$ vulcanizates have a higher $\tan \delta$, which causes a decrease in the elastic behavior compared with the control sample due to the decreasing rubber-filler interaction with the decreasing surface area of CBp. However, the height of the $\tan \delta$ peak reduced with the increase of the Op content. The results suggest that increasing the Op content causes an increase in the elastic behavior. This is probably due to the increased crosslinking density.

- In this work, the variations in the specific surface area, ash content and sulfur content of the carbon blacks and also the variations in the chemical composition of the process oils were found to cause significant changes in the properties of the NR/SBR blends. If the CBp and Op are modified, before adding them to the rubber recipe, they may improve certain properties of the rubber blends.

\section{Acknowledgements}

The authors acknowledge the support of the Coordination Committee of Scientific Research projects of Aksaray University, Turkey (Project no: 2014-20).

\section{References}

[1] Lamminmäki J., Li S., Hanhi K.: Feasible incorporation of devulcanized rubber waste in virgin natural rubber. Journal of Materials Science, 41, 8301-8307 (2006). DOI: $10.1007 / \mathrm{s} 10853-006-1010-\mathrm{y}$

[2] Adhikari B., De D., Maiti S.: Reclamation and recycling of waste rubber. Progress in Polymer Science, 25, 909-948 (2000).

DOI: 10.1016/S0079-6700(00)00020-4

[3] Karabork F., Pehlivan E., Akdemir A.: Characterization of styrene butadiene rubber and microwave devulcanized ground tire rubber composites. Journal of Polymer Engineering, 34, 543-554 (2014).

DOI: $10.1515 /$ polyeng-2013-0330

[4] Karger-Kocsis J., Mészáros L., Bárány T.: Ground tyre rubber (GTR) in thermoplastics, thermosets, and rubbers. Journal of Materials Science, 48, 1-38 (2013). DOI: $10.1007 / \mathrm{s} 10853-012-6564-2$

[5] Laresgoiti M. F., Caballero B. M., de Marco I., Torres A., Cabrero M. A., Chomón M. J.: Characterization of the liquid products obtained in tyre pyrolysis. Journal of Analytical and Applied Pyrolysis, 71, 917-934 (2004). DOI: $10.1016 /$ j.jaap.2003.12.003

[6] Helleur R., Popovic N., Ikura M., Stanciulescu M., Liu D.: Characterization and potential applications of pyrolytic char from ablative pyrolysis of used tires. Journal of Analytical and Applied Pyrolysis, 58-59, 813824 (2001).

DOI: 10.1016/S0165-2370(00)00207-2

[7] Yousefi A. A., Ait-Kadi A., Roy C.: Effect of used-tirederived pyrolytic oil residue on the properties of polymer-modified asphalts. Fuel, 79, 975-986 (2000).

DOI: 10.1016/S0016-2361(99)00216-1

[8] Kebritchi A., Firoozifar H., Shams K., Jalali-Arani A.: Effect of pre-devulcanization and temperature on physical and chemical properties of waste tire pyrolytic oil residue. Fuel, 112, 319-325 (2013).

DOI: $10.1016 /$ j.fuel.2013.04.054

[9] Kyari M., Cunliffe A. M., Williams P. T.: Characterization of oils, gases, and char in relation to the pyrolysis of different brands of scrap automotive tires. Energy Fuels, 19, 1165-1173 (2005).

DOI: $10.1021 / \mathrm{ef049686x}$

[10] Aguado R., Olazar M., Vélez D., Arabiourrutia M., Bilbao J.: Kinetics of scrap tyre pyrolysis under fast heating conditions. Journal of Analytical and Applied Pyrolysis, 73, 290-298 (2005).

DOI: 10.1016/j.jaap.2005.02.006

[11] Fernández A. M., Barriocanal C., Alvarez R.: Pyrolysis of a waste from the grinding of scrap tyres. Journal of Hazardous Materials, 203-204, 236-243 (2012). DOI: 10.1016/j.jhazmat.2011.12.014

[12] Roy C., Chaala A., Darmstadt H.: The vacuum pyrolysis of used tires: End-uses for oil and carbon black products. Journal of Analytical and Applied Pyrolysis, 51, 201-221 (1999). DOI: $10.1016 / \mathrm{S} 0165-2370(99) 00017-0$ 
[13] Martínez J. D., Murillo R., García T.: Production of carbon black from the waste tires pyrolysis. Boletín del Grupo Español Carbón, 30, 10-14 (2013).

[14] Du A., Zhang Z., Wu M.: The effect of pyrolytic carbon black prepared from junked tires on the properties of ethylene-propylene-diene copolymers (EPDM). Express Polymer Letters, 3, 295-301 (2009). DOI: $10.3144 /$ expresspolymlett.2009.37

[15] Du A. H., Wu M. S., Su C. Y., Chen H.: The characterization of pyrolytic carbon black prepared from used tires and its application in styrene-butadiene rubber (SBR). Journal of Macromolecular Science Part B: Physics, 47, 268-275 (2008).

DOI: $10.1080 / 00222340701748768$

[16] Cataldo F.: Preparation of pyrolytic carbon black from scrap tire rubber crumb and evaluation in new rubber compounds. Macromolecular Materials and Engineering, 290, 463-467 (2005).

DOI: $10.1002 /$ mame.200400388

[17] Norris C. J., Hale M., Bennett M.: Pyrolytic carbon: Factors controlling in-rubber performance. Plastics, Rubber and Composites, 43, 245-256 (2014). DOI: $10.1179 / 1743289814$ Y.0000000088

[18] Jie Z., Yong-rong Y., Xiao-hong R., Siegfried S.: Investigation of reinforcement of the modified carbon black from wasted tires by nuclear magnetic resonance. Journal of Zhejiang University SCIENCE A, 7, 1440 1446 (2006). DOI: 10.1631/jzus.2006.A1440

[19] Jie Z., Shengji W., Tianming Y., Zhengmiao X.: Modified pyrolytic carbon black from scrap tires and its reinforcement performance in natural rubber. in 'International Conference on Computer Distributed Control and Intelligent Environmental Monitoring, Changsha, Hunan, China' 472-475 (2011).

DOI: 10.1109/CDCIEM.2011.82

[20] Delchev N., Malinova P., Mihaylov M., Dishovsky N.: Effect of the modified solid product from waste tyres pyrolysis on the properties of styrene-butadiene rubber based composites. Journal of Chemical Technology and Metallurgy, 49, 525-534 (2014).

[21] Leblanc J. L., Roy C., Mirmiran S., Benallal B., Schwerdtfeger A. E.: The plasticizing properties of heavy oils obtained from the vacuum pyrolysis of used tires. Kaustschuk und Gummi Kunststoffe, 49, 194 199 (1996).

[22] Darmstadt H., Roy C., Kaliaguine S., Joo C. S., Ryoo R.: Pore structure and graphitic surface order of mesoporous carbon molecular sieves by low-pressure nitrogen adsorption. in 'International Conference on Carbon, Lexington, USA' p.9 (2001).

[23] Pantea D., Darmstadt H., Kaliaguine S., Roy C.: Heattreatment of carbon blacks obtained by pyrolysis of used tires. Effect on the surface chemistry, porosity and electrical conductivity. Journal of Analytical and Applied Pyrolysis, 67, 55-76 (2003).

DOI: $\underline{10.1016 / \mathrm{S} 0165-2370(02) 00017-7}$
[24] Kaminsky W., Mennerich C.: Pyrolysis of synthetic tire rubber in a fluidised-bed reactor to yield 1,3-butadiene, styrene and carbon black. Journal of Analytical and Applied Pyrolysis, 58-59, 803-811 (2001). DOI: $10.1016 / \mathrm{S} 0165-2370(00) 00129-7$

[25] Manoj K. C., Kumari P., Unnikrishnan G.: Cure characteristics, swelling behaviors, and mechanical properties of carbon black filler reinforced EPDM/NBR blend system. Journal of Applied Polymer Science, 120, 2654-2662 (2011). DOI: $10.1002 /$ app.33476

[26] Donnet J. B.: Carbon black: Science and technology. CRC Press, New York (1993).

[27] Litvinov V. M., Steeman P. A. M.: EPDM-carbon black interactions and the reinforcement mechanisms, as studied by low-resolution ${ }^{1} \mathrm{H}$ NMR. Macromolecules, 32, 8476-8490 (1999). DOI: $10.1021 / \mathrm{ma99} 10080$

[28] Li Z. H., Zhang J., Chen S. J.: Effects of carbon blacks with various structures on vulcanization and reinforcement of filled ethylene-propylene-diene rubber. Express Polymer Letters, 2, 695-704 (2008). DOI: $10.3144 /$ expresspolymlett.2008.83

[29] Wang M-J.: Effect of polymer-filler and filler-filler interactions on dynamic properties of filled vulcanizates. Rubber Chemistry and Technology, 71, 520589 (1998). DOI: $10.5254 / 1.3538492$

[30] Zweifel H., Maier R. D., Schiller M.: Plastics additives handbook. $6^{\text {th }}$ ed, Hanser Press, Munich (2009).

[31] Brydson J. A.: Rubbery materials and their compounds, Elsevier, London (1988).

[32] Sombatsompop N.: Dynamic mechanical properties of SBR and EPDM vulcanisates filled with cryogenically pulverized flexible polyurethane foam particles. Journal of Applied Polymer Science, 74, 1129-1140 (1999). DOI: $10.1002 /($ SICI) 1097-4628(19991031)74:5<1129 $\because$ AID-APP9>3.0.CO;2-Q

[33] Zaimova D., Bayraktar E., Katundi D., Dishovsky N.: Elastomeric matrix composites: Effect of processing conditions on the physical, mechanical and viscoelastic properties. Journal of Achievements in Materials and Manufacturing Engineering, 50, 81-91 (2012).

[34] Gonzalez L., Rodriguez A., Valentin J. L., MarcosFernandez A., Posadas P., Kunstst K. G.: Conventional and efficient cosslinking of natural rubber. Kautschuk und Gummi Kunststoffe, 58, 638-643 (2005).

[35] Al-Hartomy O. A., Al-Solamy F., Al-Ghamdi A., Dishovsky N., Ivanov M., Mihaylov M., El-Tantawy F.: Influence of carbon black structure and specific surface area on the mechanical and dielectric properties of filled rubber composites. International Journal of Polymer Science, 521985/1-521985/8 (2011). DOI: $\underline{10.1155 / 2011 / 521985}$ 
[36] Chuayjuljit S., Imvittaya A., Na-Ranong N., Potiyaraj P.: Effects of particle size and amount of carbon black and calcium carbonate on curing characteristics and dynamic mechanical properties of natural rubber. Journal of Metals, Materials and Minerals, 12, 51-57 (2002).

[37] Zhou X-W., Zhu Y-F., Liang J.: Preparation and properties of powder styrene-butadiene rubber composites filled with carbon black and carbon nanotubes. Materials Research Bulletin, 42, 456-464 (2007).

DOI: $10.1016 /$ j.materresbull.2006.06.027

[38] Terrill E. R., Centea M., Evans L. R., MacIsaac Jr. J. D.: Dynamic mechanical properties of passenger and light truck tire treads. Report No. DOT HS 811 270, U.S. Department of Transportation, National Highway Traffic Safety Administration, p.28 (2010).

[39] Waddell W. H., Bhakuni R. S., Barbin W. W., Sandstrom P. H.: Pneumatic tire compounding. The Goodyear Tire and Rubber Company, Akron (1990).
[40] Ko J. Y., Prakashan K., Kim J. K.: New silane coupling agents for silica tire tread compounds. Journal of Elastomers and Plastics, 44, 549-562 (2012).

DOI: $10.1177 / 0095244312439489$

[41] Kim W-S., Lee D-H., Kim I-J., Son M-J., Kim W., Cho S-G.: SBR/organoclay nanocomposites for the application on tire tread compounds. Macromolecular Research, 17, 776-784 (2009).

DOI: $10.1007 / \mathrm{BF} 03218614$

[42] Eirich F. R.: Science and technology of rubber. Academic Press, New York (1978).

[43] Dai S., Ao G., Kim M. S.: Reinforcement of rubbers by carbon black fillers modified by hydrocarbon decomposition. Journal of Industrial and Engineering Chemistry, 13, 1162-1168 (2007). 